\title{
Comparison of the two routes of video endoscopic inguinal lymphadenectomy in vulvar cancer: a systematic review and a single-center experience
}

\author{
Lixia Luan^, Rui Chen, Yang Yang, Fangfang Xue, Wenying Wang \\ Department of Obstetrics and Gynecology, First Affiliated Hospital of Xi'an Medical University, Xi'an, China \\ Contributions: (I) Conception and design: L Luan, W Wang; (II) Administrative support: R Chen, W Wang; (III) Provision of study materials or \\ patients: All authors; (IV) Collection and assembly of data: L Luan, Y Yang, F Xue; (V) Data analysis and interpretation: L Luan, R Chen; (VI) \\ Manuscript writing: All authors; (VII) Final approval of manuscript: All authors. \\ Correspondence to: Dr. Wenying Wang. Department of Obstetrics and Gynecology, First Affiliated Hospital of Xi'an Medical University, Xi'an 710000, \\ China. Email: 563694923@qq.com.
}

Background: Video endoscopic inguinal lymphadenectomy (VEIL) has fewer complications than open surgery for vulva cancer. No high-level evidence comparing the efficacy and safety of the two routes of VEIL (VEIL-H and VEIL-L) is available.

Methods: We performed a comprehensive literature search for reports on VEIL for vulva cancer from 2000 to 2020 and reviewed our experience. Data extraction includes patients' characteristics, perioperative indicators, postoperative complications, and cancer recurrence.

Results: A total of 11 eligible studies were included in the systematic review. Nine studies included only one route of VEIL, and the other two studies directly compared the two routes of VEIL. The average operation time of the VEIL-L group was 85 (range, 33-180.12) minutes, and that of the VEIL-H group was 112 (range, 35-170.79) minutes. The average blood loss of the VEIL-L group was 9 (range, 5-30) mL, and that of the VEIL-H group was 96 (range, 5.5-214.8) $\mathrm{mL}$. The average number of intraoperatively removed lymph nodes in the VEIL-L group was 9 (range, 7.5-13.2), and that in the VEIL-H group was 14 (range, 9.5-16). No significant difference was observed in the cancer recurrence rate between the two groups. We found similar results in our cohort study.

Conclusions: The operation time, intraoperative blood loss, and time of drainage of the VEIL-L procedure seemed less than those of the VEIL-H procedure. VEIL-L and VEIL-H were equivalent in the efficacy of lymph node dissection, surgery-related complications, and cancer recurrence rate.

Keywords: Vulva cancer; video endoscopic inguinal lymphadenectomy (VEIL); routes; complication; cancer recurrence

Submitted Aug 08, 2020. Accepted for publication Nov 27, 2020.

doi: $10.21037 /$ tcr-20-2690

View this article at: http://dx.doi.org/10.21037/tcr-20-2690

\section{Introduction}

Vulvar cancer is a relatively rare gynecological tumor, accounting for $5 \%$ of gynecological reproductive system tumors (1). According to the US cancer statistics, the US is expected to have about 6,120 new cases of vulvar cancer and about 1,350 deaths in 2020 (1). The main metastatic pathways of vulvar cancer are local spread to nearby organs, hematological metastasis, and lymph node metastasis.

^ ORCID: 0000-0001-5491-2329. 
Among them, inguinal lymph nodes are the first stop of lymph node metastasis of vulvar cancer. Lymph node metastasis is the most important independent risk factor for the prognosis of vulvar cancer (2-5). Therefore, the guideline recommends that all patients with International Federation of Gynecology and Obstetrics (FIGO) stage Ib or above lesions should have at least an ipsilateral inguinal lymphadenectomy (6).

The traditional open inguinal lymphadenectomy (OIL) is associated with high rates of postoperative complications, mainly including infection of the incision in the groin area, necrosis, lymphatic leakage, and lymphedema of the lower extremities (7-9). Several studies have shown that video endoscopic inguinal lymphadenectomy (VEIL) is feasible and has fewer complications than OIL (10-13). VEIL is performed using two routes: VEIL through the subcutaneous route of the lower extremities (VEIL-L) and VEIL through the subcutaneous route of the lower abdomen (VEIL-H). So far, no high-level evidence comparing the two routes of VEIL is available partially because of the low morbidity of vulvar cancer. By collecting and synthesizing the existing clinical research data and our experience, the present study aims to compare the surgical effects and the incidence of short- and long-term complications of the two surgical routes. We present the following study in accordance with the PRISMA reporting checklist (available at http://dx.doi.org/10.21037/tcr-202690).

\section{Methods}

\section{Systematic review}

We searched reports on vulvar cancer in PubMed and Cochrane Library using the following search terms: lymph node dissection, lymphadenectomy, endoscopy, laparoscopy, vulvar cancer, etc. (search query see Appendix 1). All relevant literature from January 1, 2000, to March 1, 2020 were retrieved. Moreover, manual testing of the literature catalogs included in the study was conducted to determine other eligible studies.

The inclusion criteria included patients with clinical or pathological diagnosis of vulvar cancer and endoscopic inguinal lymph node dissection. At the same time, the article should include the perioperative indicators of the patient, including but not limited to intraoperative blood loss, operation time, number of lymph node dissection, hospital stay, days with drainage tube, postoperative complications, and cancer recurrence. Study types included clinical trials, cohort studies, case-control studies, and case series. Data extraction included the first author, publication date, patient sample size, FIGO stage, pathological classification, and so on. Two researchers (YY and FX) independently performed study selection and data extraction and assessed the bias risk of the included studies using the Cochrane Collaboration's tool for assessing the risk of bias. Differences were resolved according to the opinion of another reviewer (Prof. WW).

\section{Cobort study}

Patients who had been diagnosed with vulvar cancer by pathology and treated with VEIL in the First Affiliated Hospital of Xi'an Medical University between May 2014 and December 2019, were included. Patients treated with VEIL-H or VEIL-L were included in the VEIL-H or VEIL-L group, respectively. The inclusion criteria were as follows: (I) preoperative pathological biopsy to confirm the diagnosis of vulvar cancer with FIGO stage Ib or above; (II) treated with VEIL; (III) no other adjuvant treatment before surgery. The exclusion criteria were as follows: (I) patients undergoing OIL; (II) clinically palpable enlarged lymph nodes; (III) patients with distant metastasis found on abdominal ultrasound and chest radiograph. The clinical and prognosis indicators were prospectively collected and followed up, and the differences of these indicators between the two groups were compared.

The study was conducted by the Declaration of Helsinki (as revised in 2013). The study was approved by the institutional review board of the First Affiliated Hospital of Xi'an Medical University (No. XYYFY2020LSK-025), and the written informed consent from patients was waived.

\section{Statistical analysis}

The cumulative incidence of clinical outcomes was calculated, and the rates were compared using the chisquare test or Fisher's exact test in systematic analysis. Because most studies did not provide standard deviations, a comprehensive analysis of continuous variables could not be achieved. In our cohort study, measurement data were expressed by median (IQR), and count data were expressed by rate. The mean comparison between the two groups was performed by Kruskal-Wallis rank-sum test. Rate comparison was performed by Fisher's exact test. Using a two-sided test, $\mathrm{P}<0.05$ was considered statistically significant. We used Empower (R) (www.empowerstats.com; 


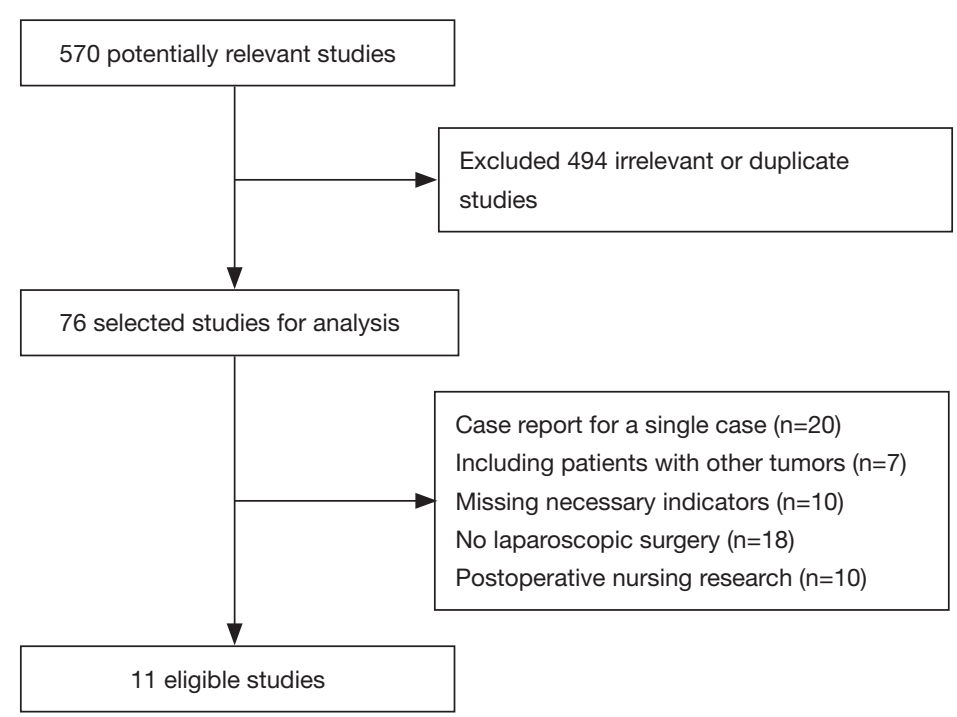

Figure 1 Flowchart of the selection process for studies included in the systematic review.

$\mathrm{X} \& \mathrm{Y}$ solutions, Inc., Boston, MA, USA) and R software, version 3.1 .2 (http://www.r-project.org) for statistical analyses.

\section{Results}

\section{Systematic review}

Using the above search strategy, 570 potential related studies were initially identified. By reading the title and abstract, a total of 76 potentially relevant articles were selected. After reading the full text, a total of 11 eligible studies (11-21) were included in the final review (Figure 1). Table 1 summarizes the key features and basic information of the selected studies. We used the evidence level of the Oxford Centre for Evidence-Based Medicine in 2011 to assess the quality of evidence (22). The included studies are all grade 4 . Among them, four are retrospective cohort studies, and the rest are case series studies. These studies were all at high risk of bias. Nine studies included only one approach of VEIL, and the studies of Naldini (20) and Zhang (21) compared VEIL with traditional OIL. Two other studies directly compared the two routes of VEIL $(11,17)$. In the end, VEIL-L was used in seven groups (114 patients, 178 sides), and VEIL-H was used in six groups (98 patients, 151 sides). The average age of patients ranged from 47.2 to 70.5 years old. A total of 185 patients had squamous cell carcinoma, accounting for $87.3 \%$ of the total number. Pathological staging was mainly stage I.
The relevant indicators of endoscopic surgery (operation time, blood loss, number of lymph node dissection, etc.) are shown in Table 2. All 11 studies retained the saphenous vein. Mathevet et al. (14) reported that two patients underwent OIL instead of VEIL due to accidental injury of the femoral vein during operation. The great saphenous vein of one patient in the VEIL-H group (17) was injured during the operation, and the remaining operations were completed. The average operation time of the VEIL-L group was 85 (range, 33-180.12) min, and that of the VEIL-H group was 112 (range, 35-170.79) min, which was longer than the former. Three articles described the amount of blood loss as small or $<5 \mathrm{~mL}(14,16,19)$. For statistical convenience, blood loss was measured by $5 \mathrm{~mL}$. The average blood loss of the VEIL-L group was 9 (range, 5-30) mL, and that of the VEIL-H group was 96 (range, 5.5-214.8) mL, which was significantly higher than the former. The average number of intraoperatively removed lymph nodes in the VEIL-L group was 9 (range, 7.5-13.2), and that in the VEIL-H group was 14 (range, 9.5-16). In eight studies, the intraoperative or postoperative pathological lymph node metastasis and lymph node infiltration rates were $21.1 \%$ (24 cases) in the VEIL-L group and $24.5 \%$ (24 cases) in the VEIL-H group. No statistically significant difference was observed in the lymph node infiltration rate between the two groups $(\mathrm{P}=0.622)$.

Table 2 shows the postoperative recovery and short-term complications of the two groups. The hospital stay in the VEIL-L group was 3-15.01 days, and that in the VEIL-H 
Table 1 Characteristics of studies included in the systematic review

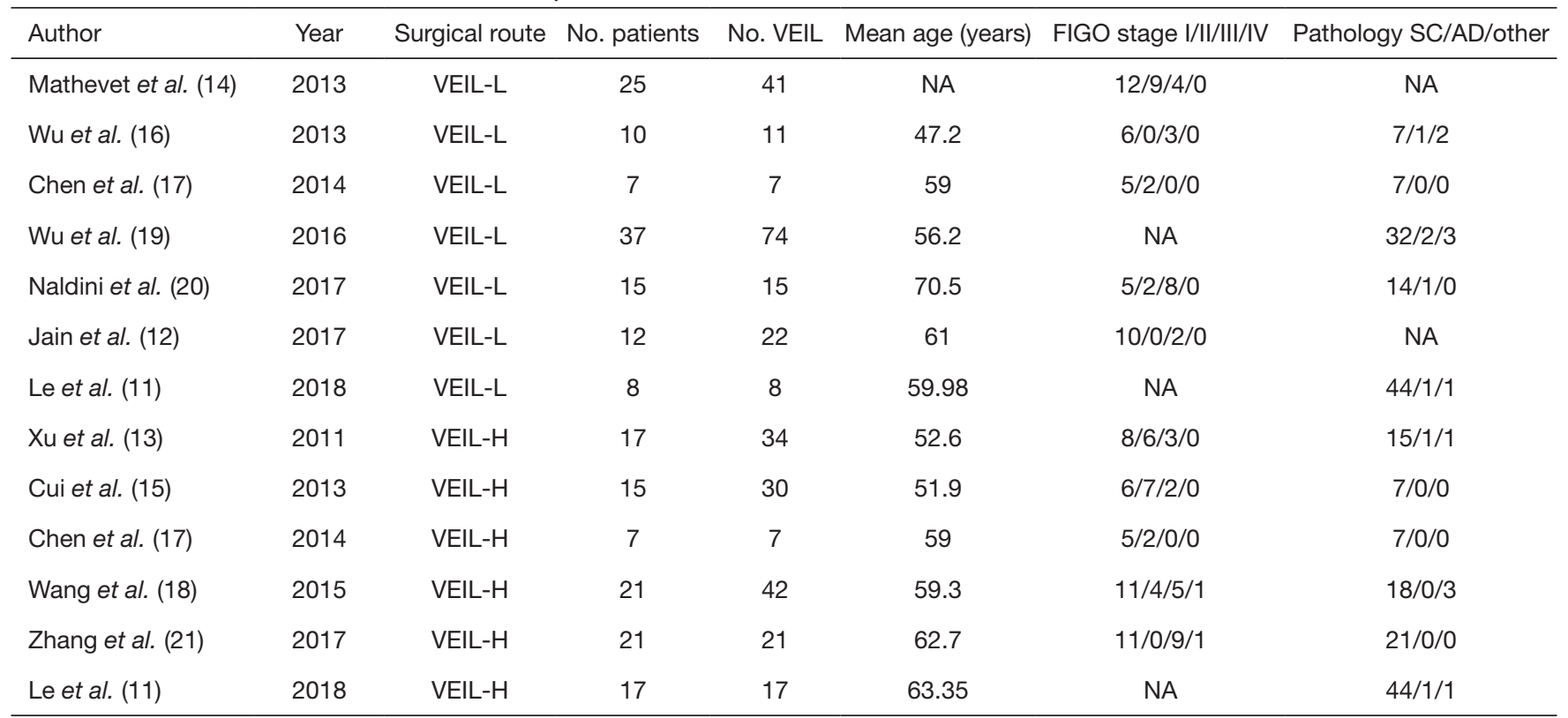

FIGO, International Federation of Gynecology and Obstetrics; VEIL, video endoscopic inguinal lymphadenectomy; SC, squamous carcinoma; AD, adenocarcinoma; NA, not applicable.

Table 2 Surgery related conditions and postoperative complications in the included studies

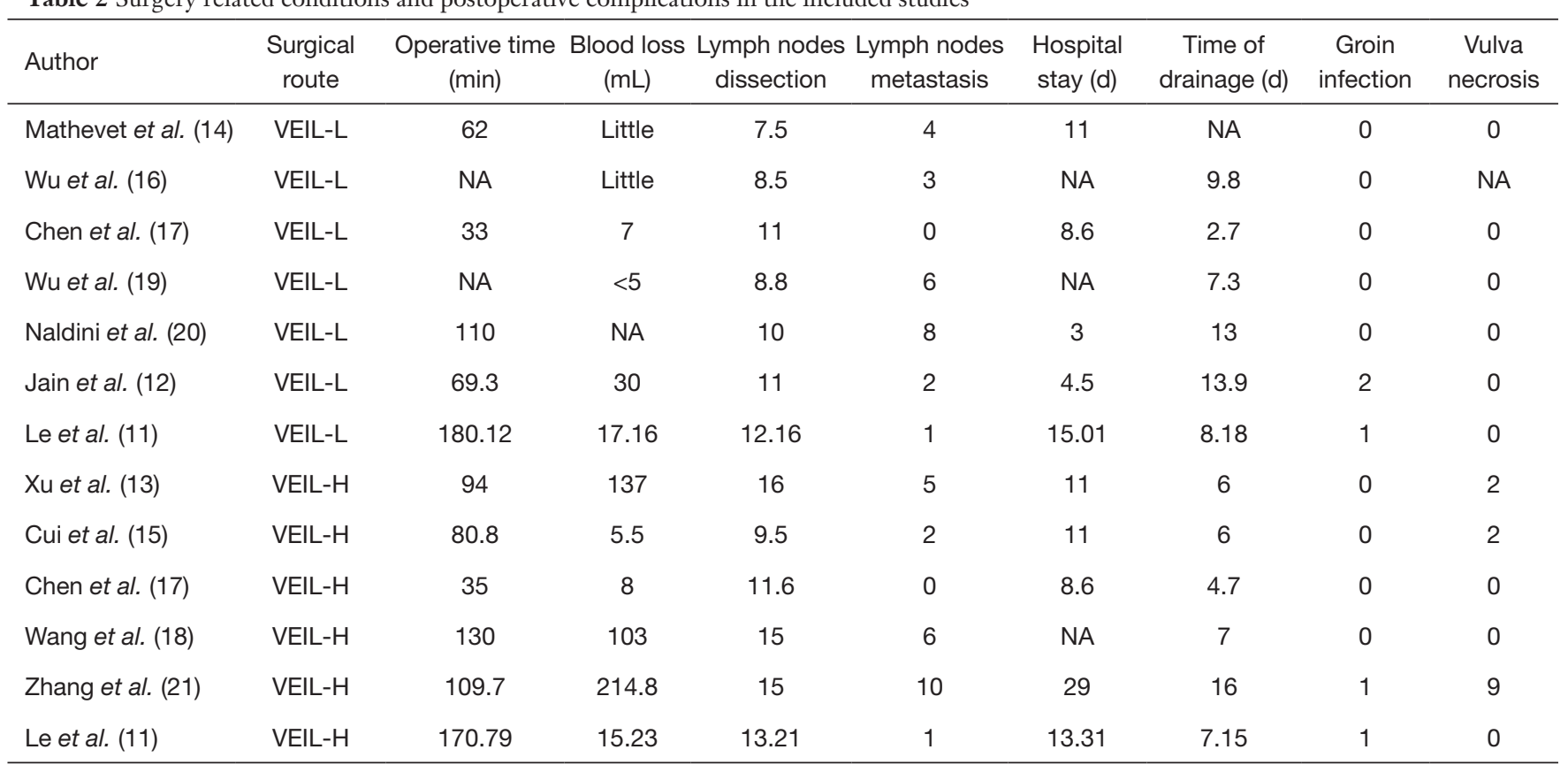

FIGO, International Federation of Gynecology and Obstetrics; VEIL, video endoscopic inguinal lymphadenectomy; NA, not applicable. 
Table 3 The patient's clinical characteristics and surgery-related conditions in our center

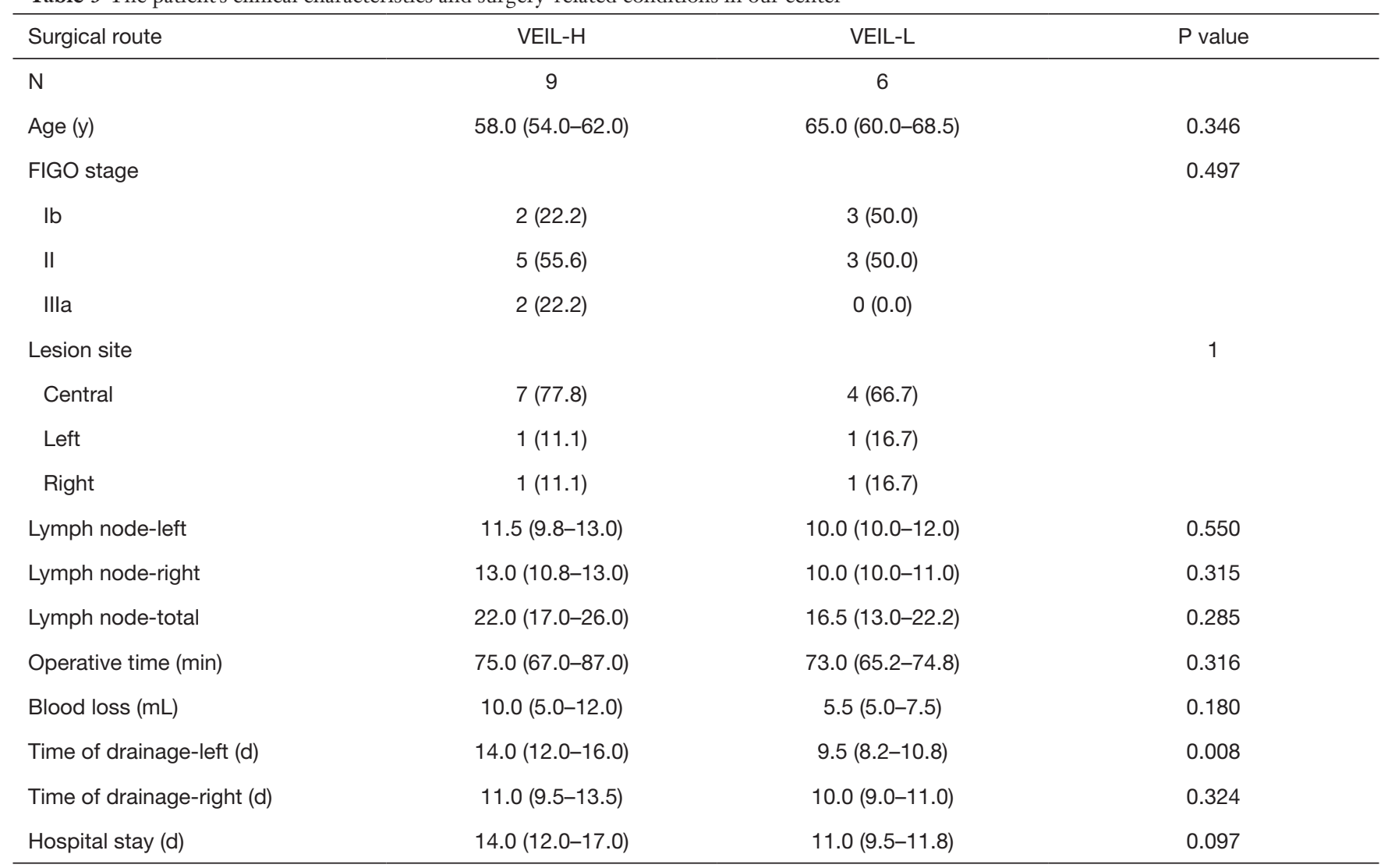

Data are expressed as median (Q1-Q3) or n (\%). FIGO, International Federation of Gynecology and Obstetrics; VEIL, video endoscopic inguinal lymphadenectomy.

group was 8.6-29 days. The days with the drainage tube was $9.1(2.7-13.9)$ days in the VEIL-L group and 8.5 (4.7-16) days in the VEIL-H group. Three cases of groin infection after the operation were observed in the VEIL-L group, whereas two cases were observed in the VEIL-H group. No necrosis was noted in the inguinal surgery area in both groups. There were 16 cases $(14.0 \%)$ of lymph cysts in the VEIL-L group after the operation and 5 cases $(5.1 \%)$ in the VEIL-H group. The difference between the two groups was statistically significant $(\mathrm{P}=0.037)$. Nine of the 11 studies mentioned postoperative recurrence. Five patients (4.4\%) in the VEIL-L group had a recurrence in the surgical area during the 1-67-month follow-up period; 5 patients (5.1\%) in the VEIL-H group also experienced cancer recurrence during the follow-up period (3-162 months).

\section{Cobort study}

A total of 15 patients met the inclusion criteria (Table S1), with a median age of 60 (range, 50-76) years. The pathological type of lesion in these patients was squamous carcinoma. According to FIGO 2009 staging of vulvar cancer (6), five cases were stage $\mathrm{Ib}$, eight cases were stage II, and two cases were stage IIIa. Among them, four cases were unilateral vulvar cancer, and VEIL was performed on the ipsilesional side (2 VEIL-H and 2 VEIL-L). Eleven cases with the central type were treated with bilateral VEIL (7 VEIL-H and 4 VEIL-L). The age, FIGO stage, and lesion site were similar between the two groups.

All patients were not converted to OIL during operation, and no serious complications occurred. As shown in Table 3, the median operation time of the VEIL-H group was 75 (IQR: 67-87) min, and that of the VEIL-L group was 73 (IQR: 65-74) $\mathrm{min},(\mathrm{P}=0.316)$. The blood loss in the VEIL-L group was lower than that in the VEIL-H group (median: 5.5 vs. $10 \mathrm{~mL}, \mathrm{P}=0.180$ ). No significant difference was observed in the number of unilateral (left/right: $\mathrm{P}=0.550 / 0.315)$ and bilateral $(\mathrm{P}=0.285)$ inguinal lymph node 
dissections. However, two patients underwent pelvic lymph node dissection as the frozen pathological results of the intraoperative lymph node suggested lymph node metastasis, and the result of pelvic lymph node pathological test was negative after surgery. The drainage tube placement time in the VEIL-L group seemed shorter than that in the VEIL-H group (left/right: $\mathrm{P}=0.008 / 0.324)$. A similar trend was found in the hospital stay $(\mathrm{P}=0.097)$. No patients had complications of skin edema, inguinal skin necrosis, or venous thrombosis of the lower extremities. One patient in the VEIL-L group recovered after a second suture of a unilateral groin infection 19 days after the operation (12th day after extubation). One patient in the VEIL-H group had a groin lymphatic cyst. During the median follow-up period of 3.0 years, one case (intraoperative lymph node-positive) relapsed in the right lower extremity puncture hole half a year after surgery. Local lesion resection was performed, and local $50 \mathrm{~Gy} / 25 \mathrm{~F} / 5 \mathrm{~W}$ radiotherapy was administered. The case had not relapsed so far. The remaining 14 patients have not yet experienced relapse or metastasis.

\section{Discussion}

VEIL is performed in the subcutaneous space without wounds in the groin area. It can effectively reduce the incidence of skin necrosis and poor wound healing in the groin area of open surgery, significantly improve the quality of life of patients, and achieve the same surgical effect as OIL $(12,20,21,23)$. Previous studies also suggest that VEIL is not only suitable for patients with early vulvar cancer but also for patients with lymph node metastasis $(15,17,19)$. At present, VEIL is performed in two routes: VEIL-L and VEIL-H. The choice of surgery depends on the patient's tumor location, local skin conditions, and surgeon's habits and experience.

Most of the 11 studies included in this review showed that the operation time of the VEIL-H group was slightly higher than that of the VEIL-L group, and the blood loss of the latter was significantly lower than that of the former. This may be because the patients in the VEIL-H group were placed in a supine position, and the endoscopic camera system was placed along the long axis of the thigh $(23,24)$. Then, the camera system may have limited movement, and the surgeon must extend above the patient's thigh to operate the surgical instruments placed on both sides. Moreover, the entrances of equipment for VEIL-L are located outside of the thigh (10). Therefore, the operator can easily operate outside of the operation area, which is more ergonomic.
This convenience may be the reason for the shortened operation time and amount of bleeding in this study.

Neither previous studies nor our results have found any significant differences in postoperative extubation time, local necrosis, infection of the groin area, lymphatic fistula, lymphedema, etc. of the two routes. However, the systematic review of previous studies suggested that the incidence of postoperative lymphatic cyst complications was higher in the VEIL-L group than in the VEIL-H group $(\mathrm{P}=0.037)$. This may be due to the VEIL-H incision in the upper abdomen and no obvious scars in the lower limbs, which has less impact on local lymphatic reflux. This was consistent with the study of Elbalka et al. (25), and more research results may need to be included to analyze this difference in the future.

The important indicators to evaluate the pros and cons of the surgical method are postoperative cancer recurrence and patient's 5-year survival evaluation. Previous studies have shown that VEIL can obtain the same effect of lymph node dissection as traditional open surgery $(16,26)$. From the existing research data, we believe that VEIL-L and VEIL-H are equivalent in lymph node dissection and cancer recurrence rate. In reviewing previous studies, 5 patients $(4.4 \%)$ in the VEIL-L group reported cancer recurrence in the surgical area, and 5 patients $(5.1 \%)$ in the VEIL-H group also had similar recurrence rates. In our study, one patient in the VEIL-H group had metastasis in the puncture site 6 months after surgery. Butler et al. (27) suggested that local recurrence after vulvar cancer surgery is due to fewer than eight lymph nodes being removed, whereas Sopracordevole et al. (28) proposed a limit of six. Baiocchi et al. (29) believe that the prognosis is poor when fewer than 12 bilateral lymph nodes were dissected in patients with positive inguinal lymph nodes. The patient mentioned above had a total of 17 lymph nodes removed from both sides of the groin during the operation, but she was diagnosed with vulvar squamous cell carcinoma IIIa stage. Moreover, intraoperative pathological examination revealed lymph node metastasis. Thus, this patient had high risk factors for poor prognosis. However, judging the prognosis simply from the number of lymph nodes removed may not be accurate enough. KleinJan et al. (30) found that marking with blue dye and radiolabeled technetium could identify the scope of sentinel lymph nodes in various types of tumor patients, which was applicable to open and endoscopic surgery. Currently, sentinel node excision is being increasingly practiced for appropriate patients in many centers (6). Studies have found that this technology 
is associated with a similar recurrence rate compared with complete lymphadenectomy (31). It may help in improving the accuracy of VEIL and reducing the incidence of lymphedema and other local complications. However, this procedure is only recommended for early vulvar cancer, and we should be wary of the false-negative rate with sentinel node biopsy (32-34).

Our study has the following limitations: (I) the evidence level of the included studies was low, all were retrospective analysis, the characteristics of the two groups of patients might be uneven, and the statistical methods and reporting indicators of the studies were not uniform. Thus, there were difficulties in synthesizing various research data. Some results could only be described but were not conclusive. (II) The included studies had a short follow-up time and could not obtain more information about recurrence. (III) Our studies only included 15 cases. In the future, studies with better design and long-term follow-up are needed to verify the safety and effectiveness of the two procedures.

\section{Conclusions}

The operation time, intraoperative blood loss, and time of drainage of the VEIL-L seemed less than those of the VEIL-H. VEIL-L and VEIL-H were equivalent in the efficacy of lymph node dissection, surgery-related complications, and cancer recurrence rate. Studies with better design are needed to further compare the two routes of VEIL.

\section{Acknowledgments}

Thanks to the language editing service provided by ShineWrite.com.

Funding: None.

\section{Footnote}

Reporting Checklist: The authors have completed the PRISMA reporting checklist. Available at http://dx.doi. org/10.21037/tcr-20-2690

Data Sharing Statement: Available at http://dx.doi. org/10.21037/tcr-20-2690

Peer Review File: Available at http://dx.doi.org/10.21037/tcr20-2690
Conflicts of Interest: All authors have completed the ICMJE uniform disclosure form (available at http://dx.doi. org/10.21037/tcr-20-2690). The authors have no conflicts of interest to declare.

Ethical Statement: The authors are accountable for all aspects of the work in ensuring that questions related to the accuracy or integrity of any part of the work are appropriately investigated and resolved. The study was conducted by the Declaration of Helsinki (as revised in 2013). The study was approved by the institutional review board of the First Affiliated Hospital of Xi'an Medical University (No. XYYFY2020LSK-025), and the written informed consent from patients was waived.

Open Access Statement: This is an Open Access article distributed in accordance with the Creative Commons Attribution-NonCommercial-NoDerivs 4.0 International License (CC BY-NC-ND 4.0), which permits the noncommercial replication and distribution of the article with the strict proviso that no changes or edits are made and the original work is properly cited (including links to both the formal publication through the relevant DOI and the license). See: https://creativecommons.org/licenses/by-nc-nd/4.0/.

\section{References}

1. Siegel RL, Miller KD, Jemal A. Cancer statistics, 2020. CA Cancer J Clin 2020;70:7-30.

2. Baiocchi G, Rocha RM. Vulvar cancer surgery. Curr Opin Obstet Gynecol 2014;26:9-17.

3. Woelber L, Mahner S, Voelker K, et al. Clinicopathological prognostic factors and patterns of recurrence in vulvar cancer. Anticancer Res 2009;29:545-52.

4. Raspagliesi F, Hanozet F, Ditto A, et al. Clinical and pathological prognostic factors in squamous cell carcinoma of the vulva. Gynecol Oncol 2006;102:333-7.

5. Giulia M, Fragomeni SM, Inzani F, et al. Molecular pathways in vulvar squamous cell carcinoma: implications for target therapeutic strategies. J Cancer Res Clin Oncol 2020;146:1647-58.

6. Hacker NF, Eifel PJ, van der Velden J. Cancer of the vulva. Int J Gynaecol Obstet 2015;131 Suppl 2:S76-83.

7. Wills A, Obermair A. A review of complications associated with the surgical treatment of vulvar cancer. Gynecol Oncol 2013;131:467-79.

8. Soliman AA, Heubner M, Kimmig R, et al. Morbidity 
of inguinofemoral lymphadenectomy in vulval cancer. ScientificWorldJournal 2012;2012:341253.

9. Gaarenstroom KN, Kenter GG, Trimbos JB, et al. Postoperative complications after vulvectomy and inguinofemoral lymphadenectomy using separate groin incisions. Int J Gynecol Cancer 2003;13:522-7.

10. Nayak SP, Pokharkar H, Gurawalia J, et al. Efficacy and safety of lateral approach-video endoscopic inguinal lymphadenectomy (L-VEIL) over open inguinal block dissection: a retrospective study. Indian J Surg Oncol 2019;10:555-62.

11. Le A, Xiong J, Wang Z, et al. Endoscopy-assisted inguinal lymphadenectomy in vulvar cancer. Arch Gynecol Obstet 2018;297:1277-83.

12. Jain V, Sekhon R, Giri S, et al. Robotic-assisted video endoscopic inguinal lymphadenectomy in carcinoma vulva: our experiences and intermediate results. Int J Gynecol Cancer 2017;27:159-65.

13. $\mathrm{Xu} \mathrm{H}$, Wang D, Wang Y, et al. Endoscopic inguinal lymphadenectomy with a novel abdominal approach to vulvar cancer: description of technique and surgical outcome. J Minim Invasive Gynecol 2011;18:644-50.

14. Mathevet P, Schettini S, Roy M, et al. Inguinoscopy or video-endoscopy inguinal lymph node dissection. Trocar J Gynecol Surg Endosc 2013. Available online: http:// thetrocar.com/inguinoscopy-for-vulvar-cancer/

15. Cui ZY, Wang YF, Chen GW, et al. Application of video endoscopic inguinal lymphadenectomy in radical vulvectomy for carcinoma. Zhonghua Yi Xue Za Zhi 2013;93:1653-6.

16. Wu Q, Zhao YB, Sun ZH, et al. Clinical application of endoscopic inguinal lymph node resection after lipolysis and liposuction for vulvar cancer. Asian Pac J Cancer Prev 2013;14:7121-6.

17. Chen G, Wang Y, Wang Y, et al. Video endoscopic inguinal lymphadenectomy via hypogastric/limb subcutaneous approach for early-stage vulvar cancer. Zhonghua Yi Xue Za Zhi 2014;94:39-42.

18. Wang H, Li L, Yao D, et al. Preliminary experience of performing a video endoscopic inguinal lymphadenectomy using a hypogastric subcutaneous approach in patients with vulvar cancer. Oncol Lett 2015;9:752-6.

19. Wu Q, Gong Z, Zhao Y, et al. Video endoscopic inguinal lymphadenectomy via 3-incision lateral approach for vulvar cancers: our preliminary outcome of 37 cases. Int J Gynecol Cancer 2016;26:1706-11.

20. Naldini A, Rossitto C, Pacelli F, et al. The video endoscopy inguinal lymphadenectomy for vulvar cancer: a pilot study. Taiwan J Obstet Gynecol 2017;56:281-5.

21. Zhang M, Chen L, Zhang X, et al. A comparative study of video endoscopic inguinal lymphadenectomy and conventional open inguinal lymphadenectomy for treating vulvar cancer. Int J Gynecol Cancer 2017;27:1983-9.

22. OCEBM Levels of Evidence Working Group. The Oxford 2011 Levels of Evidence. Oxford Centre for EvidenceBased Medicine. Available online: https://www.cebm.net/ wp-content/uploads/2014/06/CEBM-Levels-of-Evidence2.1.pdf

23. Wang S, Du P, Tang X, et al. Comparison of efficiency of video endoscopy and open inguinal lymph node dissection. Anticancer Res 2017;37:4623-8.

24. Tobias-Machado M, Tavares A, Molina WJ, et al. Video endoscopic inguinal lymphadenectomy (VEIL): minimally invasive resection of inguinal lymph nodes. Int Braz J Urol 2006;32:316-21.

25. Elbalka SS, Taha A, Srinivas C, et al. Short-term surgical outcomes of standard and lateral video endoscopic inguinal lymphadenectomy: a multinational retrospective study. J Laparoendosc Adv Surg Tech A 2020;30:373-7.

26. Schwentner C, Todenhofer T, Seibold J, et al. Endoscopic inguinofemoral lymphadenectomy--extended follow-up. J Endourol 2013;27:497-503.

27. Butler JS, Milliken DA, Dina R, et al. Isolated groin recurrence in vulval squamous cell cancer (VSCC). The importance of node count. Eur J Gynaecol Oncol 2010;31:510-3.

28. Sopracordevole F, Clemente N, Giorda G, et al. Number of nodes removed with inguinofemoral lymphadenectomy and risk of isolated groin recurrence in women with FIGO stage IB-II squamous cell vulvar cancer. Int J Gynecol Cancer 2018;28:1600-5.

29. Baiocchi G, Cestari FM, Rocha RM, et al. Does the count after inguinofemoral lymphadenectomy in vulvar cancer correlate with outcome? Eur J Surg Oncol 2013;39:339-43.

30. KleinJan GH, van Werkhoven E, van den Berg NS, et al. The best of both worlds: a hybrid approach for optimal pre- and intraoperative identification of sentinel lymph nodes. Eur J Nucl Med Mol Imaging 2018;45:1915-25.

31. Van der Zee AG, Oonk MH, De Hullu JA, et al. Sentinel node dissection is safe in the treatment of early-stage vulvar cancer. J Clin Oncol 2008;26:884-9.

32. Hampl M, Hantschmann P, Michels W, et al. Validation of the accuracy of the sentinel lymph node procedure in patients with vulvar cancer: results of a multicenter study in Germany. Gynecol Oncol 2008;111:282-8. 
33. Levenback CF, Ali S, Coleman RL, et al. Lymphatic mapping and sentinel lymph node biopsy in women with squamous cell carcinoma of the vulva: a gynecologic oncology group study. J Clin Oncol 2012;30:3786-91.

34. Garganese G, Collarino A, Fragomeni SM, et al. Groin

Cite this article as: Luan L, Chen R, Yang Y, Xue F, Wang W. Comparison of the two routes of video endoscopic inguinal lymphadenectomy in vulvar cancer: a systematic review and a single-center experience. Transl Cancer Res 2021;10(2):1034-1042. doi: $10.21037 /$ tcr-20-2690 sentinel node biopsy and (18)F-FDG PET/CT-supported preoperative lymph node assessment in cN0 patients with vulvar cancer currently unfit for minimally invasive inguinal surgery: the GroSNaPET study. Eur J Surg Oncol 2017;43:1776-83. 


\section{Appendix 1}

\#1 ((vulvar melanoma[Title/Abstract] OR (vulvar cancer[Title/Abstract] OR ("vulvar neoplasms"[MeSH Terms] OR ("vulvar"[All Fields] AND "neoplasms"[All Fields]) OR "vulvar neoplasms"[All Fields] OR ("vulvar"[All Fields] AND "tumor"[All Fields]) OR "vulvar tumor"[All Fields])))) OR (vulvar squamous[Title/ Abstract] OR vulvar adenocarcinoma[Title/Abstract] OR vulvar carcinoma[Title/Abstract]

\#2 ((endoscopic[Title/Abstract] OR endoscopy[Title/Abstract] OR laparoscopy[Title/Abstract] OR laparoscopic[Title/Abstract] OR lymphadenectomy[Title/ Abstract])) OR lymph node dissection[Title/Abstract]

\#1 AND \#2 (Filters: Publication date from 2000/01/01 to 2020/03/01)

Table S1 Each patient's clinical characteristics and surgery-related conditions in our center

\begin{tabular}{|c|c|c|c|c|c|c|c|c|c|c|c|c|c|c|c|}
\hline Case & Age & $\begin{array}{l}\text { FIGO } \\
\text { stage }\end{array}$ & $\begin{array}{l}\text { Lesion } \\
\text { site }\end{array}$ & $\begin{array}{l}\text { Surgical } \\
\text { route }\end{array}$ & $\begin{array}{l}\text { Operative } \\
\text { time (min) }\end{array}$ & $\begin{array}{l}\text { Blood loss } \\
\text { (mL) }\end{array}$ & $\begin{array}{l}\text { Lymph } \\
\text { node left }\end{array}$ & $\begin{array}{l}\text { Lymph } \\
\text { node right }\end{array}$ & $\begin{array}{l}\text { Lymph node } \\
\text { total }\end{array}$ & $\begin{array}{l}\text { Lymph nodes } \\
\text { metastasis }\end{array}$ & $\begin{array}{c}\text { Time of } \\
\text { drainage left }\end{array}$ & $\begin{array}{c}\text { Time of } \\
\text { drainage right }\end{array}$ & $\begin{array}{l}\text { Hospital } \\
\text { stay (d) }\end{array}$ & $\begin{array}{c}\text { Groin } \\
\text { infection }\end{array}$ & $\begin{array}{l}\text { Cancer } \\
\text { recurrence }\end{array}$ \\
\hline 1 & 60 & Illa & Central & VEIL-H & 98 & 15 & 13 & 13 & 26 & 2 & 15 & 15 & 16 & 0 & 0 \\
\hline 2 & 50 & II & Central & VEIL-H & 89 & 5 & 13 & 13 & 26 & 0 & 11 & 11 & 12 & 0 & 0 \\
\hline 3 & 72 & IIla & Central & VEIL-H & 87 & 20 & 10 & 7 & 17 & 1 & 16 & 16 & 17 & 0 & 1 \\
\hline 4 & 54 & II & Central & VEIL-H & 66 & 12 & 11 & 7 & 18 & 0 & 12 & 12 & 14 & 0 & 0 \\
\hline 5 & 57 & II & Central & VEIL-H & 82 & 10 & 13 & 13 & 26 & 0 & 14 & 8 & 9 & 0 & 0 \\
\hline 6 & 58 & $\mathrm{lb}$ & Left & VEIL-H & 60 & 5 & 6 & - & 6 & 0 & 18 & - & 18 & 0 & 0 \\
\hline 7 & 62 & II & Central & VEIL-H & 71 & 5 & 9 & 13 & 22 & 0 & 19 & 9 & 19 & 0 & 0 \\
\hline 8 & 52 & $\mathrm{lb}$ & Right & VEIL-H & 67 & 5 & - & 13 & 13 & 0 & - & 10 & 12 & 0 & 0 \\
\hline 9 & 76 & II & Central & VEIL-H & 75 & 10 & 12 & 12 & 24 & 0 & 13 & 13 & 13 & 1 & 0 \\
\hline 10 & 67 & $\mathrm{lb}$ & Right & VEIL-L & 63 & 5 & - & 10 & 10 & 0 & - & 11 & 12 & 0 & 0 \\
\hline 11 & 69 & $\mathrm{lb}$ & Left & VEIL-L & 74 & 8 & 13 & - & 13 & 0 & 7 & - & 8 & 0 & 0 \\
\hline 12 & 63 & $\mathrm{lb}$ & Central & VEIL-L & 55 & 5 & 5 & 8 & 13 & 0 & 11 & 11 & 11 & 0 & 0 \\
\hline 13 & 53 & II & Central & VEIL-L & 78 & 6 & 10 & 10 & 20 & 0 & 8 & 8 & 9 & 0 & 0 \\
\hline 14 & 59 & II & Central & VEIL-L & 75 & 4 & 12 & 11 & 23 & 0 & 10 & 10 & 11 & 0 & 0 \\
\hline 15 & 71 & II & Central & VEIL-L & 72 & 8 & 10 & 13 & 23 & 0 & 9 & 9 & 19 & 0 & 0 \\
\hline
\end{tabular}

FIGO, International Federation of Gynecology and Obstetrics; VEIL, video endoscopic inguinal lymphadenectomy. 